\title{
Enantioselective Disposition after Single Dose I.V Administration of Ketorolac in Male Wistar Rats
}

\author{
Authors \\ S. K. Dubey, R. N. Saha, N. Mittapelly, A. Anand \\ Affiliation \\ Department of Pharmacy, Birla Institute of Technology \& Science, Pilani, India
}

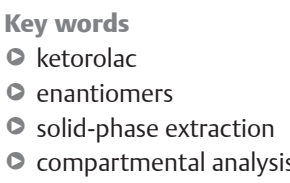

received 30.09 .2012 accepted 20.11.2012

\section{Bibliography}

DOI http://dx.doi.org/

10.1055/s-0032-1331693

Published online:

January 8, 2013

Drug Res 2013;

63: 34-37

(c) Georg Thieme Verlag KG

Stuttgart · New York

ISSN 2194-9379

\section{Correspondence}

S. K. Dubey

Department of Pharmacy

Birla Institute of Technology \&

Science

Pharmacy

$3121 \mathrm{~N}$

333031 Pilani

India

Tel.: 91/823/970 3734

Fax: + 91/15/962 3241

sunbit2000@gmail.com

\section{Abstract \\ $\nabla$}

Ketorolac, a commonly used anti-inflamatory and analgesic agent, was studied in male wistar rats. The plasma samples were analysed using chiral AGP column with UV detection. The experimental data was analysed for probable fit in the compartmental and non-compartmental models using WinNolin software. The data of (+)-R-Ketorolac and (-)-S-Ketorolac was found to fit into the compartmental as well

\section{Introduction}

$\nabla$

Ketorolac is a pyrrolizine carboxylic acid derivative, chemically, ( \pm )-5-benzoyl-2, 3-dihydro-1 H-pyrrolizine-1-carboxylic acid. It is a non steroidal antiinflammatory drug and is used principally for its analgesic activity [1] in short-term ( $<5$ days) management of moderately severe, acute pain that requires analgesia at the opioid level, usually in a postoperative setting. It is a non selective cyclooxygenase (COX) inhibitor $[2,3]$, which leads to decreased formation of precursors of prostaglandins and thromboxanes from arachidonic acid $[4,5]$. Animal studies have shown that the pharmacological activity of Ketorolac resides in the (-)-S-enantiomer and that the (+)-R-enantiomer is pharmacologically inactive [6]. The enantiomers of Ketorolac are depicted in $\bullet$ Fig. 1. The pharmacokinetics of Ketorolac have been documented in humans [7-14] and animals include dogs [15], rats [16], calves [17], rabbits [18], goats [19], sheep [20]. The purpose of the present work was to understand the enantioselective pharmacokinetic behavior of of Ketorolac after administration of single I.V dose of recemic Ketorolac in rats using compartmental and non-compartmental analysis. as non compartmental model. There was a difference between the plasma concentrations of (+)-R-Ketorolac and (-)-S-Ketorolac; the plasma concentrations of (+)-R-Ketorolac were higher than those of (-)-S-Ketorolac throughout the time course of the study. The area under the curve (AUC) of time vs. concentration profile of (+)-R-Ketorolac was found to be higher than (-)-S-Ketorolac. Volume of distribution and clearance was found to be higher for (-)-S-Ketorolac.

\section{Experimental \\ $\nabla$}

\section{Chemicals and Reagents}

Ketorolac tromethamine reference standards and pure enantiomers were purchased from TRC, Canada. Analytical grade phosphoric acid, sodium hydroxide pellets and sodium di hydrogen phosphate obtained from Merck India Limited, Mumbai, India. Milli-Q water purification system (Millipore, USA) was used for obtaining high quality HPLC grade water.

\section{Instruments}

The liquid chromatography system employed was Shimadzu HPLC (Shimadzu, Japan) with solvent delivery system of 2 pumps (Model LC-20AD, Prominence Liquid Chromatograph, Shimadzu, Japan), an auto injector (Model SIL$20 \mathrm{~A}$, Prominence Auto Sampler, Shimadzu, Japan) and photo diode array (PDA) UV detector (Model SPD-M20A, Prominence Diode Array Detector, Shimadzu, Japan). Data collection and integration was accomplished using LC Solutions 1.22 software.

Other instruments used include an electronic balance (Mettler-toledoag-135), vortex mixer (Spinh), sonicator (Toshiba, Japan), refrigerated centrifuge (Model C-24 BL, Remi, India) and deep freezer (Vestfrost). pH meter (Eutech Instru- 
<smiles>O=C(c1ccccc1)c1ccc2n1CC[C@H]2C(=O)O</smiles>

(-)- S-Ketorolac<smiles>O=C(c1ccccc1)c1ccc2n1CC[C@H]2C(=O)O</smiles>

(+)-R-Ketorolac
Fig. 1 Chemical structure of Ketorolac Enantiomers.

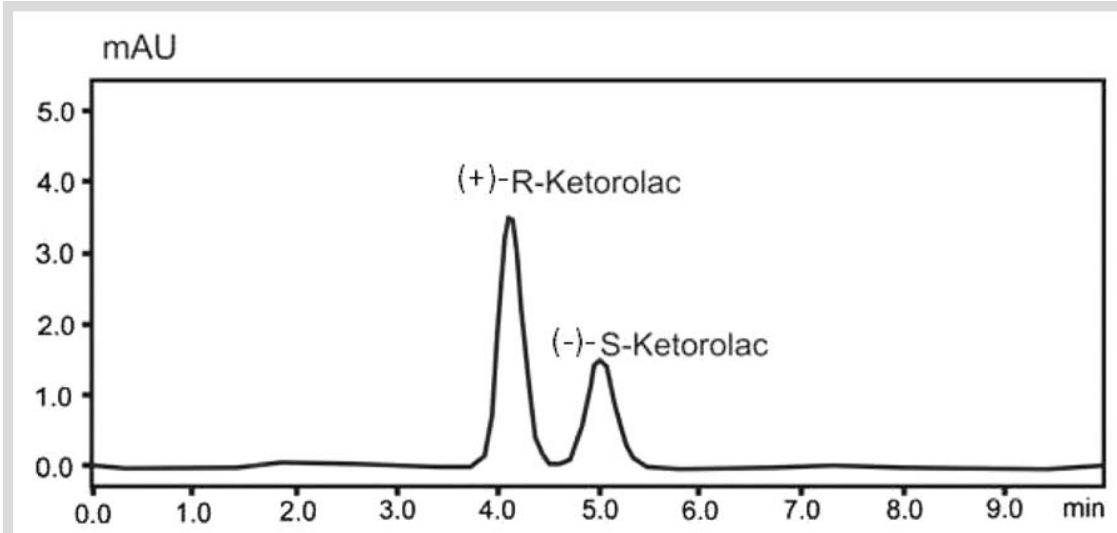

Fig. 2 Representative chromatogram of plasma sample using Chiral AGP column. ments, Singapore) was used for measuring pH of all buffer systems. Membrane filters of $0.22 \mu \mathrm{m}$ (Millipore, USA) were used for filtration of aqueous phase used in the mobile phase system.

\section{Animals}

Healthy male wistar rats weighing between 180-220g were selected for intravenous pharmacokinetic study of Ketorolac in plasma. The food for the animals withheld before $12 \mathrm{~h}$ of the study but animals had free access to drinking water. All experimental protocols were approved by the Institutional Animal Ethics Committee (IAEC).

\section{Collection of blood and separation of plasma}

Blood was collected from retro-orbital plexus of wistar rats. Clear supernatant plasma was separated from blood after the centrifugation at $3500 \mathrm{rpm}, 4^{\circ} \mathrm{C}$, for $10 \mathrm{~min}$. Samples were kept at $-20^{\circ} \mathrm{C}$ till further analysis.

\section{Extraction technique}

A simple, solid phase extraction method was followed for extraction of ketorolac from wistar rat plasma. $500 \mu \mathrm{L}$ of plasma sample was pipette into an ependroff tube and $200 \mu \mathrm{L}$ of mobile phase, $100 \mu \mathrm{L} 0 \mathrm{f} 5 \% \mathrm{v} / \mathrm{v}$ formic acid was added to it and vortexed for 2-3 min and the drug was eluted by methanol using solid phase extraction (using OASIS HLB).The eluates were evaporated to dryness at $50^{\circ} \mathrm{C}$ under a gentle nitrogen gas $\left(\mathrm{N}_{2}\right.$ ). The dry residue was re-constituted in $500 \mu \mathrm{L}$ of mobile phase, transferred to a sample-loading vial and $50 \mu \mathrm{L}$ of sample was injected into the HPLC system.

\section{Chromatographic Conditions}

A chiral-AGP column $(100 \times 4.0 \mathrm{~mm}$ I.D., particle size $5 \mu$, Chromtech Ltd, Sweden) was used for the study. The isocratic mobile phase consisted of an aqueous phase $(100 \mathrm{mM}$ sodium di-hydrogenphosphate $\mathrm{pH}$ 7.4) and isopropylalchol (96: $4 \mathrm{v} / \mathrm{v})$.
Buffer was filtered through $0.22 \mu \mathrm{m}$ Millipore membrane filter. The HPLC system was stabilized for $2 \mathrm{~h}$ at $1 \mathrm{~mL} \mathrm{~min}^{-1}$ flow rate, through baseline monitoring prior to actual analysis. Ketoroloac enantiomers were monitored at wavelength of $322 \mathrm{~nm}$. A representative chromatogram depicted in $\odot$ Fig. 2.

\section{Pharmacokinetic study}

Ketorolac formulation for intravenous (I.V) bolus administration was prepared by dissolving the drug in saline solution just before the commencement of the study. Formulation was administered through tail vein in male wistar rats. Blood samples were drawn at 2, 4, 8, 16, 32, 60, 120,240, 480 min post dose in microfuge tube pretreated with EDTA (Ethylene Diamine Tetra Acetic acid). All samples were processed according to the procedure described earlier and analyzed using the validated HPLC method. Various pharmacokinetic parameters were calculated from measured Ketorolac plasma concentrations vs. time profiles after I.V bolus administration using non-compartmental model and compartmental models in WinNonlin Professional software (Version 2.1, Pharsight Corporation, USA).

The Individual plasma concentrations vs. time plots were constructed ( $\bullet$ Fig. 3). The plasma concentration-time profiles of (-)-S-Ketorolac and (+)-R-Ketorolac after I.V administration of $3.2 \mathrm{mg} / \mathrm{kg}$ of ketorolac to rats, the area under the curve (AUC), the volume of distribution $\left(\mathrm{V}_{\mathrm{d}}\right)$, the total drug clearance $(\mathrm{CL})$ and the terminal half-life $\left(t_{1 / 2}\right)$ were determined. AUC was estimated by the trapezoidal rule and extrapolated to infinity by multiplying the last detectable concentration by the time constant of the terminal concentration decay phase. Volume of distribution was obtained by dividing the dose by the extrapolated concentration corresponding to time zero. Clearance was estimated by dividing the dose by AUC. Half-life was estimated from the slope obtained by linear regression of the terminal phase of semi-logarithmic time versus concentration plots [21]. 


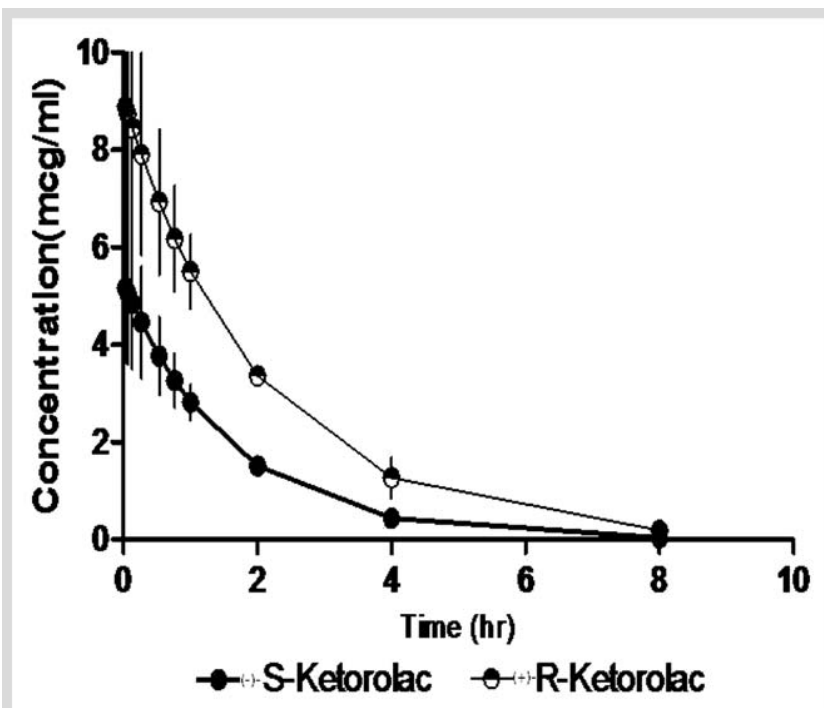

Fig. 3 Plasma concentration-time profiles of (-)-S-Ketorolac and (+)-RKetorolac after I.V administration of $3.2 \mathrm{mg} / \mathrm{kg}$ of ketorolac to rats. Each point represents the mean \pm SE of 3 rats.

\section{Statistical considerations}

Statistical analysis of pharmacokinetic data was done using the software Graph Pad Prism ver.5. The data is presented as the mean \pm SE at the $95 \%$ confidence interval. Paired t-test was used to compare the pharmacokinetic parameters between $(+)-R-$ Ketorolac and S-Ketorolac.

\section{Results and Discussion}

Plasma concentrations of (+)-R-Ketorolac exceeded those of $(-)-S-K e t o r o l a c$ throughout the time course. As the $\mathrm{AUC}_{0-\infty}$ of

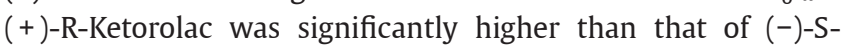
Ketorolac, the total body clearance (CL) of (-)-S-Ketorolac was significantly larger than that of R-ketorolac. The plasma concentrations of (+)-R-Ketorolac decreased more slowly than those of S-ketorolac. The elimination half-life $\left(t_{1 / 2}\right)$ of $(+)$-R-Ketorolac was significantly longer than that of (-)-S-Ketorolac. The pharmacokinetic parameters of each enantiomer and their paired t-test probability values of the difference between each enantiomer are given in $\odot$ Table 1 for one compartmental, $\odot$ Table 2 for the 2 compartmental and $\boldsymbol{\theta}$ Table $\mathbf{3}$ for the non-compartmental model.

A significant enantiomeric difference in pharmacokinetic parameters was observed for $\mathrm{V}_{\mathrm{d}}, \mathrm{CL}, \mathrm{Cmax}$, and $\mathrm{AUC}$ in all models (i.e., compartmental as well as noncompartmantal). The pharmacokinetic parameters for pharmacologically active (-)-(S)-enantiomer including $\mathrm{V}_{\mathrm{d}}$, CL were approximately twice and Cmax, AUC were approximately half, than that of its optical antipode based on a Mean \pm SE $(P<0.05)(S) /(R)$ ratio of $C \max 0.553 \pm 0.008, V_{d}$ $1.883 \pm 0.125$ CL $2.159 \pm 0.034$ and AUC $0.4609 \pm 0.004$. The statistically significant difference in the elimination rate constant and elimination half life was observed in one-compartmental model but not in 2 compartmental model and non compartmental model.
Table 1 Summary of the pharmacokinetic parameters of Ketorolac enantiomers estimated by one compartmental fitting in plasma after I.V administration of Ketorolac, $3.2 \mathrm{mg} / \mathrm{kg}$

\begin{tabular}{lccl} 
Parameter & $(+)-R-K e t o r o l a c$ & $(-)$-S-Ketorolac & Probability* \\
\hline $\mathrm{K}\left(\mathrm{hr}^{-1}\right)$ & $0.4917 \pm 0.037$ & $0.5861 \pm 0.0399$ & 0.1297 \\
$\mathrm{t}_{1 / 2}(\mathrm{hr})$ & $1.425 \pm 0.101$ & $1.193 \pm 0.0759$ & 0.14 \\
$\mathrm{Cmax}$ & $9.047 \pm 0.644$ & $4.902 \pm 0.3750$ & 0.0069 \\
$\mathrm{Vd}(\mathrm{L} / \mathrm{kg})$ & $0.1786 \pm 0.011$ & $0.330 \pm 0.0235$ & 0.0058 \\
$\mathrm{AUC}(\mu \mathrm{g} . \mathrm{hr} / \mathrm{ml})$ & $18.41 \pm 0.114$ & $8.355 \pm 0.0800$ & 0.0002 \\
$\mathrm{Cl}(\mathrm{L} / \mathrm{hr} / \mathrm{kg})$ & $0.087 \pm 0.0005$ & $0.191 \pm 0.0001$ & 0.0004 \\
${ }^{*}$ If probability value less than $0.05(\mathrm{p}<0.05)$, there exists a significant difference
\end{tabular}

between the values at $95 \%$ confidence interval

Table 2 Summary of the pharmacokinetic parameters of enantiomers estimated by 2 compartmental fitting in plasma after I.V administration of Ketorolac, $3.2 \mathrm{mg} / \mathrm{kg}$.

$\begin{array}{lccl}\text { Parameter } & (+) \text {-R-Ketorolac } & (-) \text {-S-Ketorolac } & \text { Probability }^{*} \\ \beta\left(\mathrm{hr}^{-1}\right) & 0.302 \pm 0.0105 & 0.3580 \pm 0.048 & 0.3074 \\ \mathrm{t}_{1 / 2}(\mathrm{hr}) & 2.296 \pm 0.0788 & 2.021 \pm 0.3165 & 0.377 \\ \mathrm{Cmax}(\mu \mathrm{g} / \mathrm{ml}) & 9.558 \pm 0.8429 & 5.518 \pm 0.4505 & 0.0096 \\ \mathrm{Vd}(\mathrm{L} / \mathrm{kg}) & 0.169 \pm 0.0137 & 0.291 \pm 0.02283 & 0.0060 \\ \mathrm{AUC}(\mu \mathrm{g} \cdot \mathrm{hr} / \mathrm{ml}) & 22.83 \pm 1.281 & 10.83+1.197 & 0.0194 \\ \mathrm{Cl}(\mathrm{L} / \mathrm{hr} / \mathrm{kg}) & 0.0705 \pm 0.004 & 0.155 \pm 0.011 & 0.0074 \\ { }^{*} \text { If probability value less than } 0.05(\mathrm{p}<0.05) \text {, there exists a significant difference } \\ \text { between the values at 95\% confidence interval }\end{array}$

Table 3 Summary of the pharmacokinetic parameters of Ketorolac and its enantiomers estimated by non compartmental fitting in plasma after I.V administration of Ketorolac, $3.2 \mathrm{mg} / \mathrm{kg}$.

\begin{tabular}{|c|c|c|c|}
\hline Parameter & (+)-R-Ketorolac & (-)-S-Ketorolac & Probability* \\
\hline $\mathrm{K}\left(\mathrm{hr}^{-1}\right)$ & $0.3269 \pm 0.04314$ & $0.3268 \pm 0.06195$ & 0.080 \\
\hline $\mathrm{t}_{1 / 2}(\mathrm{hr})$ & $2.208 \pm 0.3343$ & $2.283 \pm 0.4346$ & 0.022 \\
\hline Cmax $(\mu \mathrm{g} / \mathrm{ml})$ & $12.06 \pm 0.484$ & $6.708 \pm 0.224$ & 0.002 \\
\hline Vd (L/kg) & $0.2126 \pm 0.01281$ & $0.4547 \pm 0.04369$ & 0.104 \\
\hline AUC ( $\mu \mathrm{g} \cdot \mathrm{hr} / \mathrm{ml})$ & $21.28 \pm 0.7218$ & $9.785 \pm 0.3413$ & 0.008 \\
\hline $\mathrm{Cl}(\mathrm{L} / \mathrm{hr} / \mathrm{kg})$ & $0.06845 \pm 0.005453$ & $0.1434 \pm 0.01462$ & 0.080 \\
\hline
\end{tabular}

\section{Conclusions}

$\nabla$

The objective of present I.V bolus study is to clarify the fundamental pharmacokinetic properties of both $\mathrm{S}$ and R-enantiomers. The I.V dose of $3.2 \mathrm{mg} / \mathrm{kg}$ pharmacokinetic study shows that (-)-S-Ketorolac and (+)-R-Ketorolac follows 2-compartmental as well as non-compartmental models. The $\mathrm{AUC}_{0-\infty}$ of $(+)-\mathrm{R}-$ Ketorolac was higher than that of (-)-S-Ketorolac. Volume of distribution and clearance was found to be higher for (-)-SKetorolac. These findings indicated that the pharmacokinetics of Ketorolac in rats were stereo-selective.

\section{Authors' Statements \\ $\checkmark$}

\section{Animal rights}

The institutional and international guide for the care and use of laboratory animals was followed. See the experimental part for details. 


\section{Acknowledgement}

The authors are thankful to University Grant Commission, New

Delhi for extending their financial support.

\section{Conflict of Interest}

The authors declare no conflict of interest.

\section{References}

1 Rooks WH, Maloney PJ, Shott LD et al. The analgesic and anti-inflammatory profile of Ketorolac and its tromethamine salt. Drugs Exp Clin Res 1985; 11: 479-492

2 Pallapies D, Salinger A, Meyer Zum Gottesberge et al. Effects of lysine clonixinate and Ketorolac tromethamine on prostanoid release from various rat organs incubated ex vivo. Life Sci 1995; 57: 83-89

3 Galan-Herrera JF, Poo JL, Maya-Barrios JA et al. Bioavailability of two sublingual formulations of Ketorolac tromethamine $30 \mathrm{mg}$ : A randomized, open-label, single-dose, two-period crossover comparison in healthy Mexican adult volunteers. Clin Ther 2008; 30: 1667-1674

4 Zhang $Y$, Shaffer A, Portanova J et al. Inhibition of cyclooxygenase-2 rapidly reverses inflammatory hyperalgesia and prostaglandin E2 production. J Pharmacol Exp Ther 1997; 283: 1069-1075

5 Warner TD, Mitchell JA. Cyclooxygenases: new forms, new inhibitors and lessons from the clinic. FASEB J 2004; 18: 790-804

6 Guzman A, Yuste F, Toscana RA et al. Absolute configuration of (-)-5-benzoyl-1, 2-dihydro-3H-pyrrolo [1, 2-alpha] pyrrole-1-carboxylic acid, the active enantiomer of Ketorolac. J Med Chem 1986; 29: 589-591

7 Nagilla R, Deshmukh DD, Copedge KJ et al. The pharmacokinetics of ketorolac enantiomers following intramuscular administration of the racemate. J Vet Pharmacol Ther 2009; 32: 49-55

8 Jung D, Mroszczak E, Bynum L. Pharmacokinetics of ketorolac tromethamine in humans after intravenous, intramuscular and oral administration. Eur J Clin Pharmacol 1988; 35: 423-425

9 Mindy NC, Uwe C, Thomas $H$ et al. Pharmacokinetics of Single-Dose Intravenous Ketorolac in Infants Aged 2-11 Months. Anesth Analg 2011; 112: 655-660
10 Anne ML, Heidi B, Eric D et al. Ketorolac tromethamine: stereo-specific pharmacokinetics and single-dose use in postoperative infants aged 2-6 months. Paediatr Anaesth 2011; 21: 325-334

11 Kauffman RE, Lieh-Lai MW, Uy HG et al. Enantiomer-selective pharmacokinetics and metabolism of ketorolac in children. Clin Pharmacol Ther 1999; 65: 382-388

12 Hamunen K, Maunuksela EL, Sarvela J et al. Stereoselective pharmacokinetics of ketorolac in children, adolescents and adults. Acta Anaesthesiol Scand 1999; 43: 1041-1046

13 Hayball J, Wrobel J, Tamblyn JG et al. The pharmacokinetics of ketorolac enantiomers following intramuscular administration of the racemate. Br J clin Pharmac 1994; 37: 75-78

14 Drover DR, Hammer GB, Anderson BJ. The pharmacokinetics of ketorolac after single postoperative intranasal administration in adolescent patients. Anesth Analg 2012; 114: 1270-1276

15 Pasloske K, Renaud R, Burger J et al. Pharmacokinetics of ketorolac after intravenous and oral single dose administration in dogs. J Vet Pharmacol Ther 1999; 22: 314-319

16 Jamali F, Lovlin R, Corrigan BW et al. Stereospecific pharmacokinetics and toxicodynamics of ketorolac after oral administration of the racemate and optically pure enantiomers to the rat. Chirality 1999; 11: 201-205

17 Nagilla R, Deshmukh DD, Duran SH. Stereoselective pharmacokinetics of ketorolac in calves after a single intravenous and oral dose. J Vet Pharmacol Ther 2007; 30: 437-442

18 Wang M, Liu W, Lu Q. Pharmacokinetic comparison of ketorolac after intracameral, intravitreal, and suprachoroidal administration in rabbits. Neurosurgery. 2012

19 Nagilla $R$, Deshmukh $D D$, Copedge KJ et al. Enantiomeric disposition of ketorolac in goats following administration of a single intravenous and oral dose. J Vet Pharmacol Ther 2009; 32: 49-55

20 Santos Ballesteros Ros et al. Chiral pharmacokinetics of ketorolac in sheep after intravenous and intramuscular administration of the racemate. J Vet Pharmacol Ther 2001; 24: 443-446

21 Dipanjan G, Ajay K, Sunil KD et al. Liquid Chromatographic tandem mass spectrometric validated method for pharmacokinetic estimation of flecainide in human plasma. Clin Res Regul Aff 2009; 26: 24-36 